\title{
Modelling the Elastic Properties of Bi-Continuous Composite Microstructures Captured with TriBeam Serial-Sectioning
}

Paul J. Mignone ${ }^{\mathrm{a}, \mathrm{b}, 1,}$, McLean P. Echlin ${ }^{\mathrm{c}}$, Tresa M. Pollock ${ }^{\mathrm{c}}$, Trevor R. Finlayson ${ }^{\mathrm{a}}$, Daniel P. Riley, ${ }^{b, d}$, Mitchell L. Sesso ${ }^{a}$, George V. Franks ${ }^{a, b}$

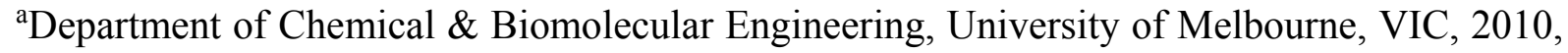
Australia

${ }^{\mathrm{b}}$ Defence Materials Technology Centre, Hawthorn, VIC, 3122, Australia

'Materials Department, University of California - Santa Barbara, Santa Barbara CA, 931065050, USA

${ }^{\mathrm{d} A u s t r a l i a n}$ Nuclear Science \& Technology Organisation, Lucas Heights, NSW, 2234, Australia

Corresponding Author: George V. Franks, gvfranks@unimelb.edu.au, +61 383449020

Other email addresses: paul_mignone@sutd.edu.sg (Paul J. Mignone); mechlin@engineering.ucsb.edu (McLean P. Echlin); pollack@enginieering.ucsb.edu (Tresa M. Pollack); trevorf@unimelb.edu.au (Trevor R. Finlayson); dry@ansto.gov.au (Daniel P. Riley); mitchell.sesso@unimelb.edu.au (Mitchell L. Sesso)

\section{Abstract}

The elastic and physical properties of a tungsten-copper (W-Cu) bi-continuous composite were predicted from microstructural data captured using TriBeam serial sectioning. The reconstructed 3D volume was converted into a Finite Element (FE) mesh. The minimum representative volume elements (RVEs) required for calculating phase volume fraction, Young's modulus and Poisson's ratio were determined. The predicted volume fraction of $\mathrm{Cu}$ and Young's modulus were found to be within $2.6 \%$, and $3.6 \%$ of the respective experimentally determined values. The minimum RVE size is found to be dependent on the material property. The variability in the required RVE size must be considered for material properties of $\mathrm{W}-\mathrm{Cu}$ and similar bi-continuous composite microstructures.

Keywords: Finite Element Method, Electron Microscopy, Microanalysis, Composites, Micromechanics, Tungsten-copper

${ }^{1}$ Present Address: (paul_mignone@sutd.edu.sg) 


\section{Introduction}

In many engineering applications, the requirements for critical system components cannot be met by any single material or alloy. Future aerospace and energy technologies will require functional materials that can effectively manage and dissipate temperatures greater than $2000^{\circ} \mathrm{C}$ and that can retain structural integrity over long thermal exposures $[1,2]$. Heterogeneous, composite-microstructure materials have been shown to withstand these extreme environments, as they provide favourable properties from their constituent phases.

Copper-infiltrated-tungsten (W-Cu) bi-continuous metal-matrix composite (MMC) materials have been shown to perform well in high-temperature applications. Optimization of the $\mathrm{W}-\mathrm{Cu}$ microstructure is required in order to improve the high -temperature properties of this material. Computational modelling and simulation have been used in conjunction with mechanical testing and characterisation to tailor the specific material properties of $\mathrm{W}-\mathrm{Cu}$ and similar heterogeneous materials.

The prediction of the physical and mechanical properties from three-dimensional (3D) microstructural representations of bi-continuous $\mathrm{W}-\mathrm{Cu}$ composites has previously been limited to functionally graded models [3] and continuous fibre-reinforced set-ups [4]. Recently, two-dimensional (2D) models created using the Voronoi tessellation technique [5] have been used to generate virtual bi-continuous $\mathrm{W}-\mathrm{Cu}$ microstructures. However, 2D stress states generated using finite element (FE) analysis cannot be directly compared to the experimentally measured properties in $\mathrm{W}-\mathrm{Cu}$ and other composites [6].

Finite element simulations using idealised, 2D microstructures under plane strain conditions have been performed elsewhere $[7,8]$. In these simulations, a simple representation of the microstructure consisting of a unit cell with a single circular void inside a square elastic-plastic medium was used, which allowed for the study of void interaction effects. The model was further simplified by treating one quarter of the cell and by applying periodic boundary conditions.

The unit cell could also be approximated through the FE analysis of axisymmetric cylindrical unit cells, as proposed by Tvergaard [9]. Both the 2D plane strain and axisymmetric unit cell techniques have been used extensively to analyse the mechanical response of particle-reinforced composites (PRCs) [10-13]. These simplified 2D unit cell methods have provided computationally inexpensive insight into the deformation behaviour of materials, however they ignore microstructural complexities such as phase connectivity and non-uniform particle distributions in PRCs, which significantly affect the deformation 
1 behaviour [6,14]. Recently, Chen et al. [15] have addressed this issue in a voxel-based, discrete, computational model for both bi-continuous and particulate composites and have produced successful results for the dependence of bulk and shear moduli on volume fraction.

Modelling efforts that are based on 3D microstructure-based FE simulations, are able to capture the alignment, aspect ratio, and distribution of the particles. Particle stresses, localised damage and debonding mechanisms have been studied using simulations that approximate the reinforcement phase of PRCs as perfect spheres [16-20].

Characterisations of $3 \mathrm{D}$ microstructure for input to $\mathrm{FE}$ simulations have been performed using non-destructive techniques such as X-ray micro-tomography [21-23]. However, dense materials such as tungsten have a high mass attenuation coefficient, making microstructural characterisation impractical with low-energy X-ray micro-tomography systems. Neutron micro-tomography is also not a viable option, because the technique currently lacks the spatial resolution to characterise the fine-grained microstructures present in $\mathrm{W}-\mathrm{Cu}$ composites [24]. Mechanical polishing-based, serial sectioning techniques have been used to characterize 3D microstructures [25,26] and in a recent approach [27], a 3D microstructure was developed from statistical analysis of a single 2D microstructure from a scanning electron microscope image. However, these approaches require significant time, financial investment, and careful polishing routines for composites containing phases with non-uniform hardness.

The TriBeam system [28,29] was used to section and capture high-resolution SEM images of the $\mathrm{W}-\mathrm{Cu}$ composite microstructures. The TriBeam consists of a femtosecond laser coupled with a FIB-SEM microscope for fast and automated 3D dataset acquisition with multiple imaging modalities, as described in more detail elsewhere [29]. Using this technique, material volume elements of several hundred microns on edge were gathered, with a submicron sectioning resolution and material removal rates four to five orders of magnitude faster than those of a gallium focused ion beam (FIB).

Without accurate microstructural information, the minimum representative volume element (RVE) (i.e., the smallest volume of microstructure in which simulations can be made to statistically represent the macroscopic properties of the composite), for $\mathrm{W}-\mathrm{Cu}$ and similar bi-continuous composites, cannot be determined accurately. While modelling a larger, more conservative RVE size will better represent the composite statistically, it comes at the cost of increased computational time and resources. An optimally defined RVE allows for the evaluation of simulations at optimal time, permitting higher degrees of freedom in the FE simulation (i.e., the investigation of non-linear effects such as plasticity, damage and debonding of material phases). 
The minimum RVE size is dependent on the specific material property of interest. Previous research has quantified this variability in RVE size for physical, mechanical, thermal and electrical properties of a material [28,30-32]. While considerable work has been conducted on determining these properties, RVE analysis of the Poission's ratio in composite microstructures, has not been extensively studied [33-35]. In addition, experimental techniques for evaluating the Poisson's ratio of composites are scarce and complex when compared with those for other mechanical properties. These techniques include uniaxial tensile testing [36,37], bulge testing [38,39], X-ray diffraction [40,41], resonance testing [42] and micro-bending techniques [43]. These limitations persist, despite Poission's ratio being an important material property used in the design of mechanical and thermo-mechanical components. Therefore, development of computational approaches for determining this property is essential for the overall improvement of material design processes.

In this investigation, serial sectioning via the Tribeam system using femtosecond laser ablation was used to capture the microstructural information in $\mathrm{W}-\mathrm{Cu}$ composites. SEM images captured during serial sectioning were segmented into constituent $\mathrm{W}$ and $\mathrm{Cu}$ phases and then aligned into binarized image stacks. The final datasets were then converted into 3D meshes that were used for finite element analysis (FEA) to simulate compressive strain. The volume fraction of $\mathrm{Cu}$, Young's modulus and Poisson's ratio of the material were determined for the collected 3D datasets and the RVE sizes for these material properties are discussed.

\section{Methodology and Material}

\subsection{Tungsten-Copper Composite (W-Cu)}

$\mathrm{W}-\mathrm{Cu}$ is a two-phase, bi-continuous, metal-matrix composite consisting of a tungsten (W) matrix phase and a copper $(\mathrm{Cu})$ reinforcement phase. Additionally, $\mathrm{W}$ and $\mathrm{Cu}$ have different atomic crystal structures (W and $\mathrm{Cu}$ being $\mathrm{BCC}$ and $\mathrm{FCC}$, respectively), large atomic radii difference of $>20 \%$, and significantly different electro-negativities $(\mathrm{W}=2.36$ and $\mathrm{Cu}=1.9)$, thus violating the Hume-Rothery rules $[44,45]$ and making them virtually immiscible. An exception to immiscibility exists when $\mathrm{W}$ and $\mathrm{Cu}$ powders undergo high-energy ball milling. In this case, dissolution of a small amount of $\mathrm{Cu}$ into $\mathrm{W}$ has been observed $[46,47]$.

$\mathrm{W}-\mathrm{Cu}$ composites are generally fabricated by $\mathrm{Cu}$ infiltration into porous $\mathrm{W}$. This process involves compacting and pre-sintering $\mathrm{W}$ powder at approximately $1300^{\circ} \mathrm{C}$. The pre-sintered blocks are submerged in molten $\mathrm{Cu}$ at approximately $1400^{\circ} \mathrm{C}$ to fill the pore space between the $\mathrm{W}$ grains. Typically, 1 to $2 \%$ of residual porosity is found in $\mathrm{W}-\mathrm{Cu}$ composites [48-50]. 
1 Other processes exist to produce thin W-Cu films such as plasma spraying [51] and electronbeam physical vapour deposition [52].

The high electrical and thermal conductivities of $\mathrm{Cu}$, combined with the high melting point $\left(3422^{\circ} \mathrm{C}\right)$ and low vapour pressure of $\mathrm{W}$, have led to $\mathrm{W}-\mathrm{Cu}$ being widely used in technologies such as electrical contacts, welding electrodes and as tools for electro-discharge machining [53-56]. For short time periods, until the $\mathrm{Cu}$ is completely consumed, W- $\mathrm{Cu}$ composites are able to withstand extreme temperature loading via $\mathrm{Cu}$ ablatively cooling the $\mathrm{W}$ structure. At high temperatures, the $\mathrm{Cu}$ melts and vaporises, extracting heat from the system and passively cooling the $\mathrm{W}$ matrix, keeping it at a temperature no more than the boiling point of the $\mathrm{Cu}$ (about $2550^{\circ} \mathrm{C}$ ). When the $\mathrm{Cu}$ reservoirs are empty, the composite becomes susceptible to high-temperature degradation and failure of the $\mathrm{W}$ matrix will occur as the temperature of the material can then increase above the boiling point of $\mathrm{Cu}[56,57]$.

For this investigation, literature values for the $\mathrm{Cu}$ volume fraction and Young's modulus of $\mathrm{W}-\mathrm{Cu}$ with $10 \% \mathrm{wt} \mathrm{Cu}$, produced by Plansee [58], were used for validating the simulations based on the TriBeam tomography W-Cu datasets. Table 1 shows these data.

Table 1. W-Cu material properties according to Plansee [58].

\begin{tabular}{l|c}
\hline Property & W-Cu10 \\
\hline $\mathrm{Cu}$ Content $(\mathrm{wt} \%)$ & 10.0 \\
$\mathrm{Cu}$ Volume Fraction (vol\%) & 19.3 \\
Density at $20^{\circ} \mathrm{C}\left(\mathrm{gcm}^{-3}\right)$ & 17.1 \\
Ew-Cu $(\mathrm{GPa})$ & 330
\end{tabular}

\subsection{Capturing the Microstructure with TriBeam Serial Sectioning}

A full description of the TriBeam sectioning methodology for the W-Cu sample is available elsewhere [28]. A summary of this work is presented as follows:

1. The femtosecond laser is focused and translated to the surface of the sample.

2. The laser beam is then scanned horizontally, parallel to the sample surface, ablating $250 \mathrm{~nm}$ of material off the top surface.

3. The sample is tilted for surface-normal electron beam imaging using secondary electrons.

4. The process is repeated until the required number of image slices is collected resulting in an image stack for 3D reconstruction. 
Images of the data set were obtained for low $(\times 500)$ and high $(\times 2500)$ magnification as shown in Figs. 1(a) and 1(b), respectively. A continuous matrix of connected W particles was observed. The percolated network of $\mathrm{Cu}$ shows little porosity at the interfaces with the $\mathrm{W}$ matrix and exhibits submicron features with high aspect ratios.
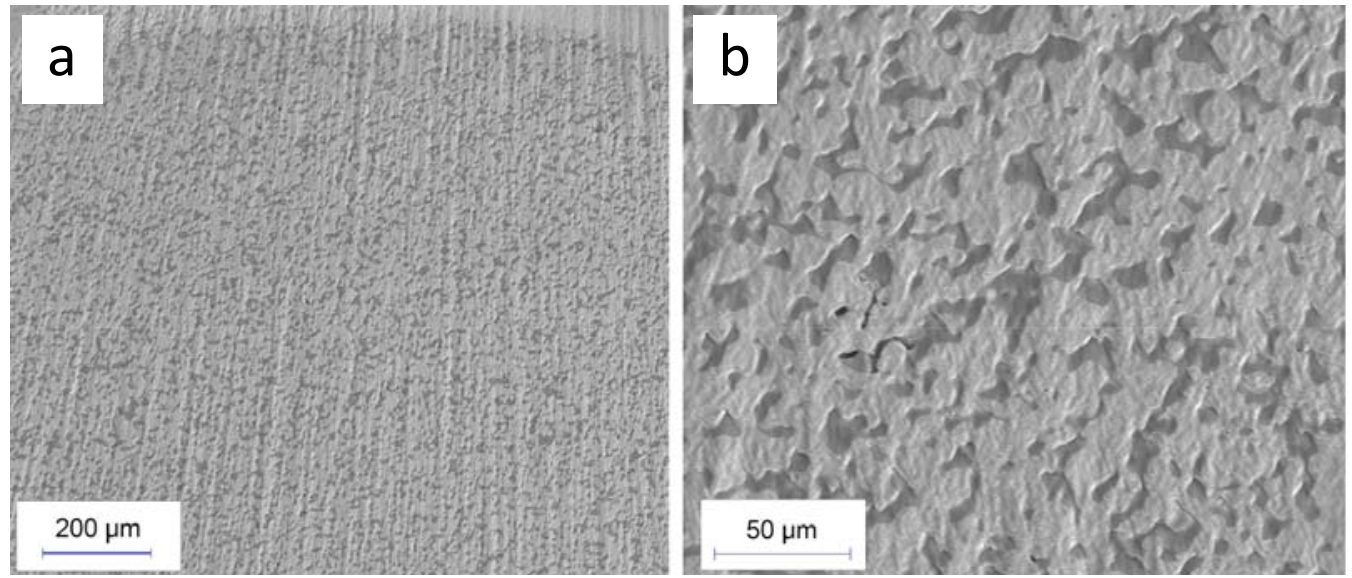

Fig. 1. W-Cu sample surface after laser ablation sectioning in the TriBeam at (a) $\times 500$ magnification and (b) $\times 2500$ magnification. The lighter and darker areas represent the $\mathrm{W}$ and $\mathrm{Cu}$ phases, respectively.

\subsubsection{Sample ablation geometry}

W-Cu samples were electrical discharged machined (EDM) and diamond polished into a series of W-Cu micropillars as shown in Fig. 2. The height of the pillars along the Z-axis in Fig. 2(b) was approximately $1 \mathrm{~mm}$ and the pillars have cross-sectional X-Y dimensions of approximately $500 \mu \mathrm{m} \times 500 \mu \mathrm{m}$ (Fig. 2(a)).
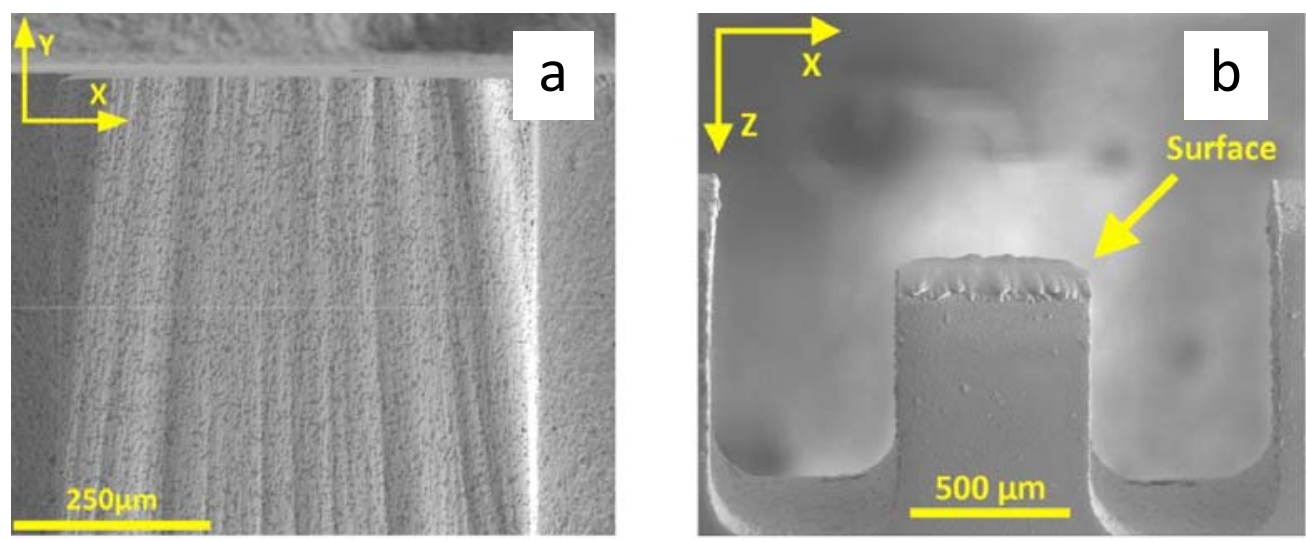

Fig. 2. SEM images of a micro-pillar sample showing (a) top view at $\times 200$ magnification and (b) side view at $\times 80$ magnification.

During the laser ablation in the TriBeam, the beam is scanned horizontally along the $\mathrm{X}$ axis (i.e., YZ plane), removing a $250 \mathrm{~nm}$ layer of $\mathrm{W}-\mathrm{Cu}$. The free surfaces surrounding the 
micropillars eliminates adjacent areas where material can redeposit and interfere with SEM imaging.

\subsection{Image Processing and FE Meshing}

The stack of images collected during TriBeam sectioning was reconstructed using a series of image processing routines to produce a binarized dataset. The 2D images were processed and binarized using ImageJ (The National Institutes of Health, USA) to segment the $\mathrm{Cu}$ and $\mathrm{W}$ into discrete phases. Template matching based registration algorithms were also used to correct for minor planar displacements that occurred during stage positioning before SEM imaging. Template matching is a technique in digital image processing that identifies corresponding features between sets of images [59]. Using this technique, common features in the image stack were identified and used to translate and align the images in the dataset.

After registration of the dataset, a band-pass filter was used to eliminate the vertical striations (curtains) caused by the laser ablation process (Fig. 2(a)). The band-pass algorithm is a frequency-based filtering technique that was used to remove the periodic vertical striations [60]. This was followed by an anisotropic diffusion filter, an iterative, non-linear filter designed to reduce image noise without removing significant parts of the image content [61]. The resulting images were then binarized into their separate $\mathrm{W}$ and $\mathrm{Cu}$ material phases.

Meshes were produced using Simpleware + FE Free, a commercial algorithm which can generate all-tetrahedral meshes. The meshes were converted into FEA input files and imported into Abaqus 6.12-1 [62], the FEA software used for the investigation. All models used four-node, 3D linear tetrahedral elements. Reliable values for material properties were assigned to the $\mathrm{W}[63]$ and $\mathrm{Cu}$ [64] phases and these data are listed in Table 2.

Table 2. Tungsten and copper material properties at room temperature, after Lowrie and Gonas [63] for W and Ledbetter [64] for $\mathrm{Cu}$.

\begin{tabular}{c|c|c|c|c|c}
\hline Material & $\begin{array}{c}\text { Density } \\
\left(\mathrm{gcm}^{-3}\right)\end{array}$ & $\begin{array}{c}\text { Bulk } \\
\text { modulus } \\
(\mathrm{GPa})\end{array}$ & $\begin{array}{c}\text { Shear } \\
\text { modulus } \\
(\mathrm{GPa})\end{array}$ & $\begin{array}{c}\text { Young's } \\
\text { modulus } \\
(\mathrm{GPa})\end{array}$ & $\begin{array}{c}\text { Poisson's } \\
\text { ratio }\end{array}$ \\
\hline $\begin{array}{c}\text { Tungsten } \\
\text { Copper }\end{array}$ & 19.15 & 307.11 & 156.71 & 408.0 & 0.28 \\
139.74 & 47.57 & 129.80 & 0.34
\end{tabular}

The interface strength between the $\mathrm{W}$ and $\mathrm{Cu}$ phases is assumed to be perfect, and thus a $\mathrm{W} / \mathrm{Cu}$ interface cannot debond during compression. This is a reasonable assumption for small deformations, where plasticity and interface debonding are negligible. Symmetric boundary 
1 conditions were enforced on three surfaces (one in each of the $\mathrm{XY}, \mathrm{XZ}$ and $\mathrm{YZ}$ planes) in order to prevent displacement in their corresponding normal directions, thereby fixing the model in 3D Cartesian space. The symmetric boundary conditions were setup in the Abaqus initial step (i.e., before loading was applied), and remained in place throughout the compressive loading step. The symmetric boundary condition corresponds to the physical assumption that, on the two sides of the boundary, the same physical processes exist [65]. The volumes of the microstructure under investigation are sufficiently large to eliminate bias and dispersion of RVE results due to boundary conditions [30].

Volume elements with cubic edge lengths (CELs) of $15 \mu \mathrm{m}, 30 \mu \mathrm{m}, 45 \mu \mathrm{m}, 60 \mu \mathrm{m}, 75 \mu \mathrm{m}$ and $90 \mu \mathrm{m}$ were sampled from within the entire 3D dataset volumes. The number of FEA models generated at each CEL sampling size can be viewed in Table 3. In the Abaqus loading step, compression simulations were performed by applying a uniform displacement load on the surface of each model for each of the principal axes (i.e., X, Y and Z). This was done to investigate potential anisotropy in the mechanical response.

Table 3. Number of volume element models at each CEL.

\begin{tabular}{c|c|c|c|c|c|c}
\hline CEL Size & $15 \mu \mathrm{m}$ & $30 \mu \mathrm{m}$ & $45 \mu \mathrm{m}$ & $60 \mu \mathrm{m}$ & $75 \mu \mathrm{m}$ & $90 \mu \mathrm{m}$ \\
\hline \# of Samples & 27 & 27 & 27 & 27 & 8 & 8
\end{tabular}

Samples were compressed to a displacement of $1.0 \%$ of CEL in each of the simulations. This compressive strain was chosen as the stiffness matrix and is assumed to be constant in linear FEA simulations, producing a linear force-displacement relationship [21].

A mesh sensitivity study on the mechanical properties was conducted on W-Cu models with CELs of $15 \mu \mathrm{m}, 30 \mu \mathrm{m}$ and $60 \mu \mathrm{m}$ using mean element volumes (i.e., mesh densities) of $0.31 \mu \mathrm{m}^{3}, 0.16 \mu \mathrm{m}^{3}$ and $0.03 \mu \mathrm{m}^{3}$ [75]. Between the three levels of mesh refinement, variations (i.e., mesh sensitivity) of the mechanical properties for the $\mathrm{W}-\mathrm{Cu}$ models were found to be less than $1.0 \%$. Due to this negligible change in results, a mesh density of 0.31 $\mu \mathrm{m}^{3}$ was used for all datasets in the RVE analysis. This level of mesh refinement, while optimal on computational resources, will ensure consistent results for models with CELs of 75 $\mu \mathrm{m}$ and $90 \mu \mathrm{m}$.

The Young's modulus and Poisson's ratio were determined using the reaction force (from the uniform displacement load) experienced from compressing the sample (F), the compression displacement $(\Delta \mathrm{d})$ and the lateral displacements. The resulting model stiffness (K) can be determined using Hooke's law (i.e., $\mathrm{K}=\mathrm{F} / \Delta \mathrm{d}$ ). Knowing the $\mathrm{CEL}$ and the sample's 
1 initial, uncompressed, cross-sectional area (A), Young's modulus can then be determined

2 (i.e., $\mathrm{E}=\mathrm{K} .(\mathrm{CEL} / \mathrm{A})$. To determine the Poisson's ratio of the sample, the average displacements on the lateral faces of the volume element were extracted from the output. For displacements along the longitudinal direction, assuming infinitesimal strains (a valid linear analysis assumption), Poisson's ratio was calculated as a ratio of lateral displacement to the compressive longitudinal displacement.

\subsection{Modelling Elastic Properties}

When two linear elastic materials are mixed to form a composite, the material properties of the composite can also be assumed to be elastic. Assuming a continuous fibre $\mathrm{Cu}$ reinforced $\mathrm{W}$ composite microstructure, the upper and lower bounds of the Young's modulus can be determined using the rule of mixtures [66]. The upper bound of the modulus occurs when the composite is loaded parallel to the fibre direction. The lower bound of the modulus occurs when the composite is loaded perpendicular to the fibre direction. In our previous work, RVE sizes were established for $\mathrm{W}-\mathrm{Cu}$ material properties, such as permeability and elastic modulus [28]. However, the rule of mixtures approach used to evaluate the elastic modulus is limited for the complex, bi-continuous microstructure of the $\mathrm{W}-\mathrm{Cu}$ material and mechanical properties such as Poisson's ratio were not investigated.

Improved analytical methods to estimate the effective elastic properties of similar heterogeneous composite materials have been developed [67-71]. Hashin and Shtrikman [69] assume the composite can be described as mechanical mixtures of a number of different isotropic and homogeneous elastic phases. Using variational principles in the linear theory of elasticity, they establish two distinct bounds for the effective elastic moduli of the composite. Analytical, material property prediction methods such as those from Budiansky [67] and Mura [70], as well as semi-empirical methods from those such as Halpin and Tsai [71] have been found to produce results within these bounds of the Hashin and Shtrikman (H\&S) criterion [6,72]. For details see equations in Hashin and Shtrikman [69] and Chawla and Shen [72].

Table 4 shows the H\&S bounds for Young's modulus (Ew-Cu) and Poisson's ratio ( $v_{\text {W-Cu}}$ ) for a W-Cu composite of $10 \mathrm{wt} \% \mathrm{Cu}$ using the $\mathrm{H} \& \mathrm{~S}$ criterion to determine bulk and shear moduli for the composite and hence the polycrystalline averages for Young's modulus and Poisson's ratio [73]. A cylindrical sample ( $8 \mathrm{~mm}$ diameter and $24 \mathrm{~mm}$ long) of a W-Cu $(10 \%$ wt $\mathrm{Cu})$ sample was compressed in uniaxial compression. The Young's modulus was measured to be $323.5 \mathrm{GPa}$ during an experiment carried out at the ENGIN-X beamline at the 
1 Rutherford-Appleton Laboratory. This is within 2.0\% of the Plansee source material literature

2 value in Table 1 [58], and both results are within the H\&S bounds.

3

Table 4. Theoretical, experimental and literature values of $\mathrm{W}-\mathrm{Cu}(10 \% \mathrm{wt} \mathrm{Cu})$ material properties.

\begin{tabular}{l|c|c|c|c}
\hline Property & H\&S (Bound 1) & H\&S (Bound 2) & Experiment & Literature \\
\hline EW-Cu $(\mathrm{GPa})$ & 317 & 335 & 323.5 & 330 \\
$v$ W-Cu & 0.293 & 0.288 & - & -
\end{tabular}

5

\section{Results and Discussion}

\subsection{Reconstructed Microstructures}

Tomographic datasets were collected using the TriBeam for datasets of $500 \times 500 \times 0.25 \mu \mathrm{m}^{3}$ in $10 \% \mathrm{wt}$ $\mathrm{Cu}, \mathrm{W}-\mathrm{Cu}$ composites. The reconstructed datasets were sampled into cubic volume elements with edge lengths between $15 \mu \mathrm{m}$ and $90 \mu \mathrm{m}$ and $\mathrm{FE}$ meshes of the microstructures were generated. Examples of $15 \mu \mathrm{m}, 30$ $\mu \mathrm{m}$ and $60 \mu \mathrm{m}$ cubes are shown in Fig. 3. The light and dark coloured regions represent the $\mathrm{W}$ and $\mathrm{Cu}$ phases, respectively. Femtosecond laser sections were made along the $\mathrm{Z}$ axis as shown in Fig. 2, with SEM imaging in the $\mathrm{X}$ $Y$ plane. Dataset reconstructions were performed using the image processing, registration, and meshing procedures described in the experimental section. No anisotropy was observed in the simulated properties calculated using the resulting FE meshes.

\subsection{Volume Fraction}

The densities of the W-Cu composite samples were measured by Archimedes' method [74]. The experimentally determined density of $17.1 \mathrm{gcm}^{-3}$ is in agreement with that
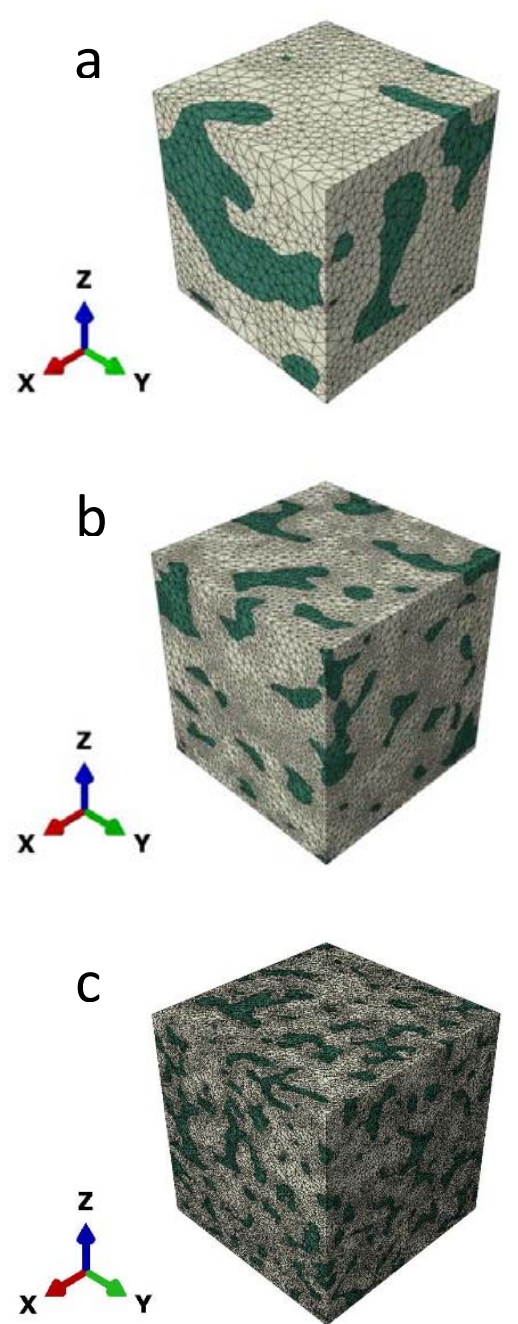

Fig. 3. Examples of finite element (FE) meshes at $15 \mu \mathrm{m}, 30 \mu \mathrm{m}$ and $60 \mu \mathrm{m}$ volume element size models. The lighter and darker regions represent the $\mathrm{W}$ and $\mathrm{Cu}$ phases, respectively. 
1 reported by the manufacturer [58], as summarized in Table 1. Using the measured density, the expected $\mathrm{Cu}$ volume fraction of 0.193 can only be calculated if the sample is assumed to have 1.2 volume percent porosity, which is consistent with the information available on the processing method. The mean $\mathrm{Cu}$ volume fraction $\left(\mathrm{V}_{\mathrm{fCu}}\right)$ and the $95 \%$ confidence interval $2 \sigma$ error bars, as measured from the 3D W-Cu datasets at different CELs, are shown in Fig. 4.

With increasing volume element size, the $\mathrm{V}_{\mathrm{fCu}}$ measurement varies from 0.196 at $15 \mu \mathrm{m}$, 0.198 at $60 \mu \mathrm{m}$, to 0.198 at $90 \mu \mathrm{m}$. For the same volume element sizes, the standard deviation reduces from 0.048 to 0.007 , and 0.006 , respectively. The $\mathrm{V}_{\mathrm{fCu}}$ at $90 \mu \mathrm{m}$ is within $2.6 \%$ of the experimentally measured $\mathrm{V}_{\mathrm{fCu}}$. The standard deviation in $\mathrm{V}_{\mathrm{fCu}}$ for a $95 \%$ confidence interval is $49.3 \%$ at $15 \mu \mathrm{m}, 7.2 \%$ at $60 \mu \mathrm{m}$, and $5.6 \%$ at $90 \mu \mathrm{m}$ volume element sizes. Therefore, an RVE size of $90 \mu \mathrm{m}$ or greater is required to obtain $\mathrm{V}_{\mathrm{fCu}}$ measurements that have $95 \%$ confidence to be within $5 \%$ of the mean value.

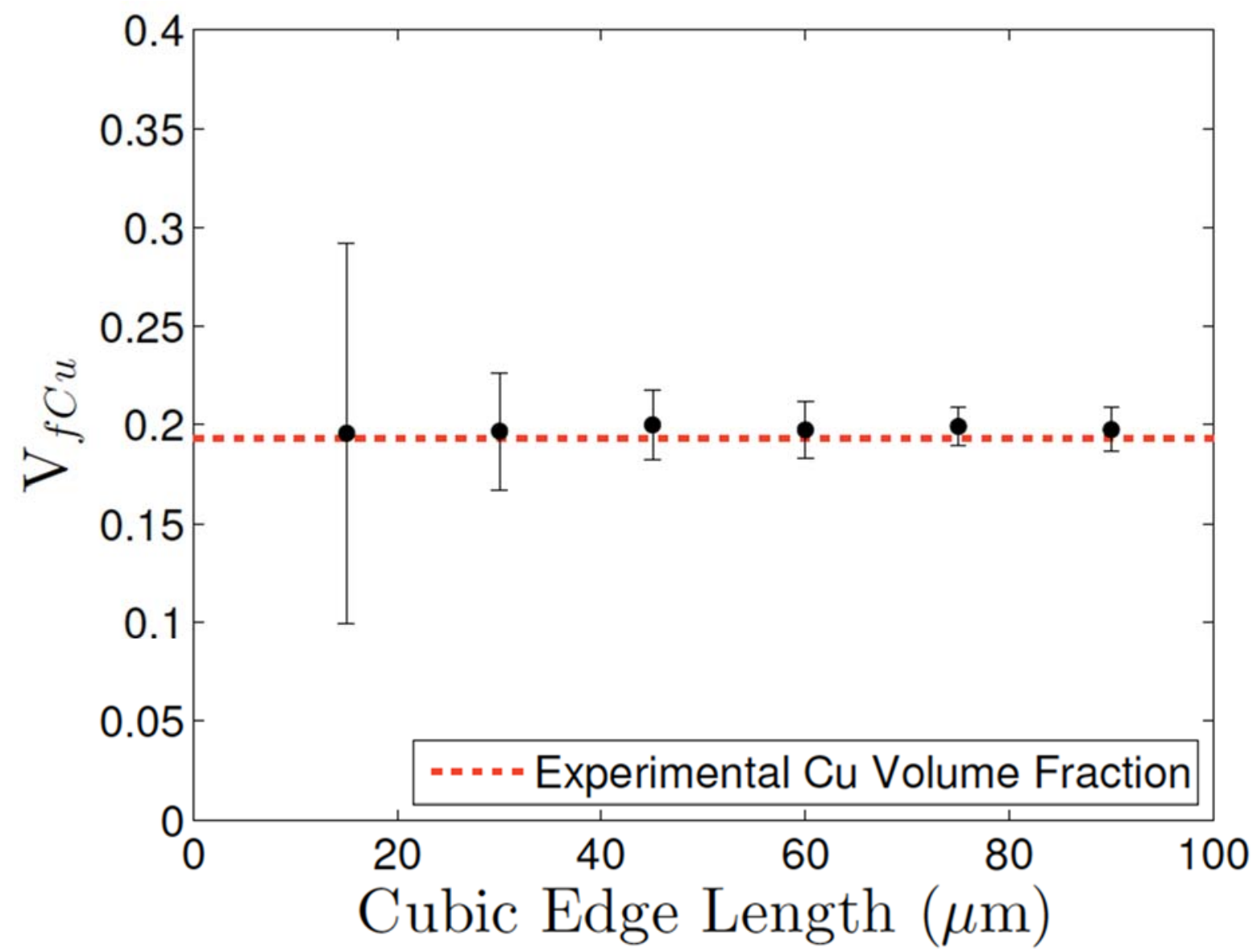

Fig. 4. $\mathrm{Cu}$ volume fraction $\left(\mathrm{V}_{\mathrm{fCu}}\right)$ at different volume element sizes. The symbols show the average value of the measurements and the error bars show the $95 \%$ confidence interval. 
The RVE analysis of Young's modulus was performed using simulated compression of the $\mathrm{W}-\mathrm{Cu}$ datasets (in the principal $\mathrm{X}, \mathrm{Y}$ and $\mathrm{Z}$ directions) at different CELs. In Fig. 5, each point represents the mean Young's modulus (Eavg) of the $\mathrm{X}, \mathrm{Y}$ and $\mathrm{Z}$ directions for all RVEs at each CEL, along with error bars plotting the 95\% confidence interval. As illustrated in Fig. 5, Eavg remains constant at $335 \mathrm{GPa}$ between CEL sizes of $15 \mu \mathrm{m}$ and $90 \mu \mathrm{m}$. The standard deviation in E decreases from $18.2 \mathrm{GPa}$ at $15 \mu \mathrm{m}$ to $3.5 \mathrm{GPa}$ at $60 \mu \mathrm{m}$ and $2.9 \mathrm{GPa}$ at $90 \mu \mathrm{m}$. The Eavg measurement at $90 \mu \mathrm{m}$ is within $3.6 \%$ of the experimental Eavg values. Although the Young's moduli results were $3.6 \%$ greater than the experimental value, an even better match to the experimental results can be obtained once the influence of internal porosity (determined to be approximately $1.2 \%$ ) is accounted for [75]. This will be discussed in a subsequent paper. The standard deviation in $E_{\text {avg }}$ for a $95 \%$ confidence interval is $10.8 \%$ at $15 \mu \mathrm{m}, 2.1 \%$ at $60 \mu \mathrm{m}$ and $1.8 \%$ at $90 \mu \mathrm{m}$. Results have been further refined to investigate the mean Young's modulus in the principal $\mathrm{X}\left(\mathrm{E}_{\mathrm{x}}\right), \mathrm{Y}\left(\mathrm{E}_{\mathrm{y}}\right)$ and $\mathrm{Z}\left(\mathrm{E}_{\mathrm{x}}\right)$ directions. Table 5 shows the Young's moduli and standard deviations $(\sigma)$ in each of the principal directions for the samples for $60 \mu \mathrm{m}$ RVE size. Differences between the modulus values in the $\mathrm{X}, \mathrm{Y}$, and $\mathrm{Z}$ directions were found to be minimal. At a volume element size of $60 \mu \mathrm{m}, \mathrm{E}_{\mathrm{x}}, \mathrm{E}_{\mathrm{y}}$ and $\mathrm{E}_{\mathrm{z}}$ are $333 \mathrm{GPa}$, $338 \mathrm{GPa}$ and $333 \mathrm{GPa}$, respectively, a difference of $1.5 \%$. For the same volume element size, the standard deviations for $\mathrm{E}_{\mathrm{x}}, \mathrm{E}_{\mathrm{y}}$ and $\mathrm{E}_{\mathrm{z}}$ are 3.1 GPa, 2.7 GPa and 2.5 GPa, respectively.

Table 5. Comparison of average elastic moduli and standard deviations in $\mathrm{X}, \mathrm{Y}$ and $\mathrm{Z}$ directions for $60 \mu \mathrm{m}$ RVE.

\begin{tabular}{c|c|c|c|c|c}
\hline $\mathrm{E}_{\mathrm{x}}(\mathrm{GPa})$ & $\sigma_{\mathrm{x}}(\mathrm{GPa})$ & $\mathrm{E}_{\mathrm{y}}(\mathrm{GPa})$ & $\sigma_{y}(\mathrm{GPa})$ & $\mathrm{E}_{z}(\mathrm{GPa})$ & $\sigma_{z}(\mathrm{GPa})$ \\
\hline 333 & 3.1 & 338 & 2.7 & 333 & 2.5
\end{tabular}




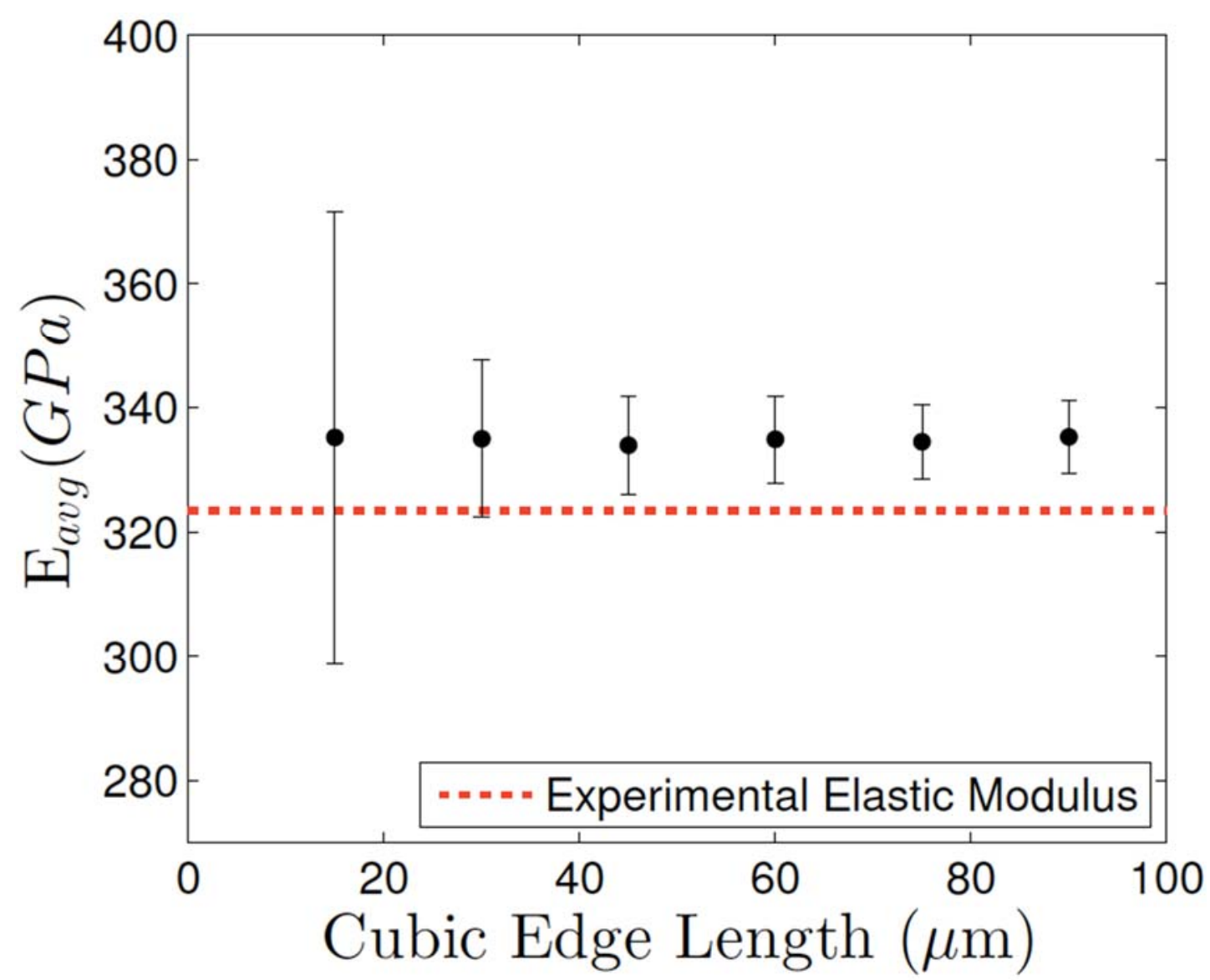

Fig. 5. Mean Young's modulus $\left(\mathrm{E}_{\mathrm{avg}}\right)$ at different volume element sizes. The symbols show the average value of the measurements and the error bars show the $95 \%$ confidence interval.

\subsection{Poisson's Ratio}

An RVE analysis of Poisson's ratio was performed by simulated compression of the W$\mathrm{Cu}$ datasets (in their principal $\mathrm{X}, \mathrm{Y}$ and $\mathrm{Z}$ directions) at different CELs. In Fig. 6, the mean Poisson's ratio ( $v_{\text {avg }}$ ) along the $\mathrm{X}, \mathrm{Y}$ and $\mathrm{Z}$ directions is shown for each volume element size, with $95 \%$ confidence interval error bars. The value of vavg changes from 0.289 at $15 \mu \mathrm{m}$ to 0.288 at $90 \mu \mathrm{m}$. The standard deviation in $v_{\text {avg }}$ decreases from 0.009 at $15 \mu \mathrm{m}$ to 0.002 at $90 \mu \mathrm{m}$, producing $v_{\text {avg }}$ variations within the $95 \%$ confidence interval of $6.0 \%$ and $1.4 \%$, respectively. The mean Poisson's ratios in the principal $X\left(v_{x y} \& v_{x z}\right), Y\left(v_{y x} \& v_{y z}\right)$ and $Z$ $\left(v_{\mathrm{zx}} \& v_{\mathrm{zy}}\right)$ directions were also investigated. Table 6 shows the Poisson's ratios and standard deviations in the measurement along each of the principal directions for samples for $60 \mu \mathrm{m}$ volume element size. At a $90 \mu \mathrm{m}$ volume element size, $v_{x y}$ and $v_{z y}$ are slightly lower than the other four values. These Poisson's ratio values were also found to be consistently lower at volume element sizes of $30 \mu \mathrm{m}$ and above. Small variations in anisotropy are observed in the 
1 Poisson's ratio, however at a volume element size of $90 \mu \mathrm{m}$ the principal values of $v_{\mathrm{zx}}$ and $v_{\mathrm{zy}}$ 2 are 0.290 and 0.284 , a difference of $2.1 \%$.

3

Table 6. Comparison of the average Poisson's ratios and standard deviatins in $\mathrm{X}, \mathrm{Y}$ and $\mathrm{Z}$ directions at $60 \mu \mathrm{m}$ volume element size.

6

\begin{tabular}{|l|l|l|l|l|}
\hline$X$ & $v_{x y}$ & $\sigma_{x y}$ & $\sigma_{x z}$ & $\sigma_{x z}$ \\
\hline & 0.285 & 0.0004 & 0.290 & 0.0007 \\
\hline$Y$ & $v_{y x}$ & $\sigma_{y x}$ & $\sigma_{y z}$ & $\sigma_{y z}$ \\
\hline & 0.289 & 0.0007 & 0.289 & 0.0006 \\
\hline$Z$ & $v_{z x}$ & $\sigma_{z x}$ & $v_{z y}$ & $\sigma_{z y}$ \\
\hline & 0.289 & 0.0009 & 0.284 & 0.0005 \\
\hline
\end{tabular}

7

8

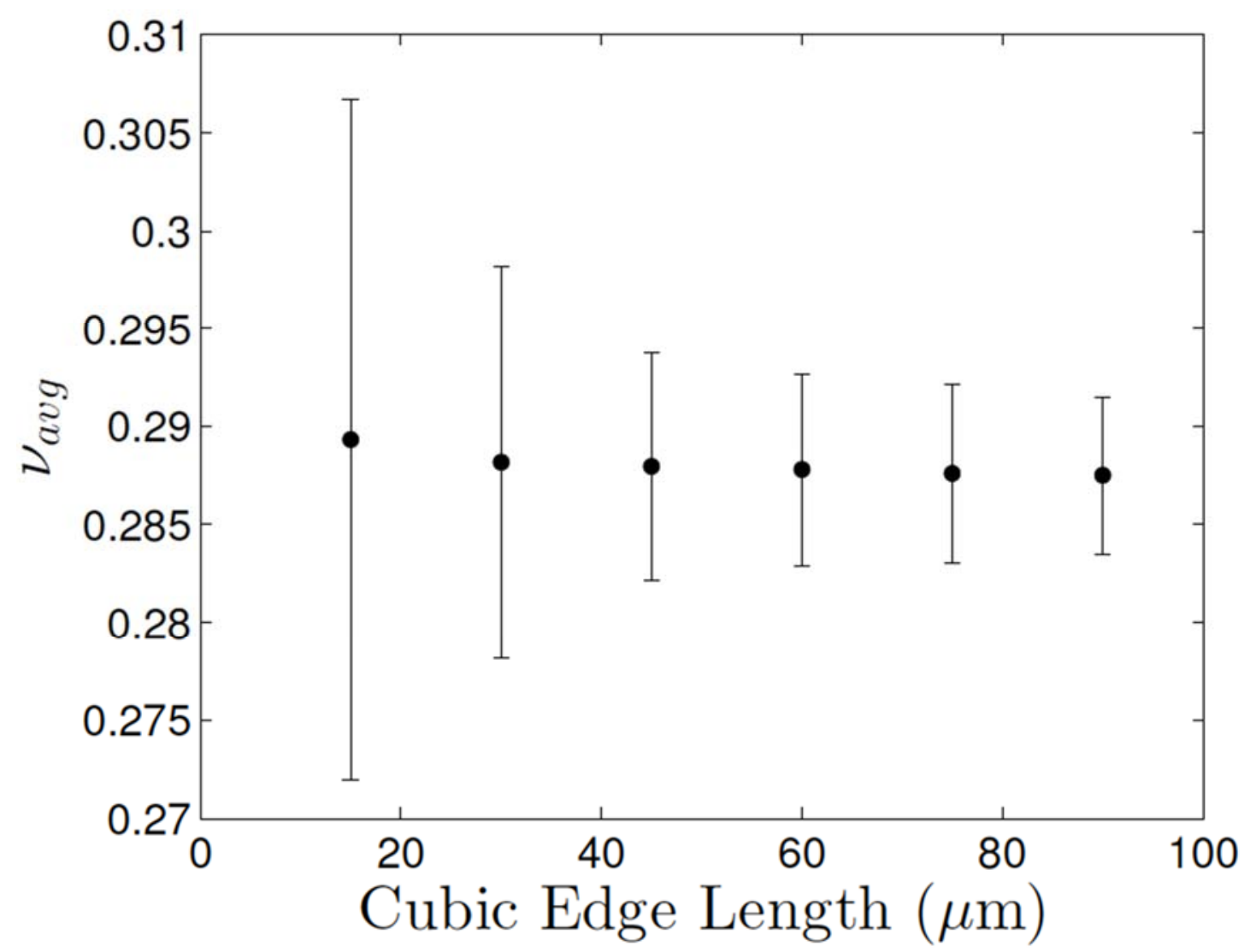

Fig. 6. Mean Poisson's ratio $\left(v_{\text {avg }}\right)$ at different volume element sizes. The symbols show the average value of the measurements and the error bars show the $95 \%$ confidence interval.

\subsection{Comparing the Statistical Variation of Properties}


In order to compare the physical and mechanical properties of the sample, the statistical variation of the $\mathrm{Cu}$ volume fraction, Young's modulus and Poisson's ratio were normalised and compared at different volume element sizes. The variability was assessed using the coefficient of variation [76]. The unbiased estimation of the coefficient of variation $\left(C O V^{*}\right)$ [77] is appropriate for use when $\mathrm{n}$ is small (Equation 1):

$$
\operatorname{COV}^{*}=\left(1-\frac{1}{4 n}\right) \frac{\sigma}{\mu}
$$

where $\mu$ and $\sigma$ are the sample mean and sample standard deviation, respectively. Fig. 7 shows the resultant $\mathrm{COV}^{*} \mathrm{~s}$ for the $\mathrm{Cu}$ volume fraction $\left(\mathrm{CVf}_{\mathrm{f}}\right)$, Young's modulus $\left(\mathrm{C}_{\mathrm{E}}\right)$ and Poisson's ratio $\left(\mathrm{C}_{v}\right)$ with respect to the volume element size. All of the properties have higher variability $\left(\mathrm{COV}^{*}\right.$ values) at smaller volume element sizes, with $\mathrm{Cvf}$ having the highest $\mathrm{COV}^{*}$. Therefore, the $\mathrm{Cu}$ volume fraction is the most sensitive microstructural descriptor to volume element size. The $\mathrm{C}_{\mathrm{Vf}}$ decreases from 0.254 at $15 \mu \mathrm{m}$ to 0.029 at $90 \mu \mathrm{m}$.

The Young's modulus, $\mathrm{C}_{\mathrm{E}}$, decreases from 0.056 at $15 \mu \mathrm{m}$ to 0.009 at $90 \mu \mathrm{m}$. $\mathrm{C}_{\mathrm{E}}$ reaches a stable value at volume element size of approximately $60 \mu \mathrm{m}$. The majority of the mechanical load of the composite is supported by stiff, high volume fraction, W phase. Therefore, minor changes in the volume fraction are observed not to vary the resulting Young's modulus significantly.

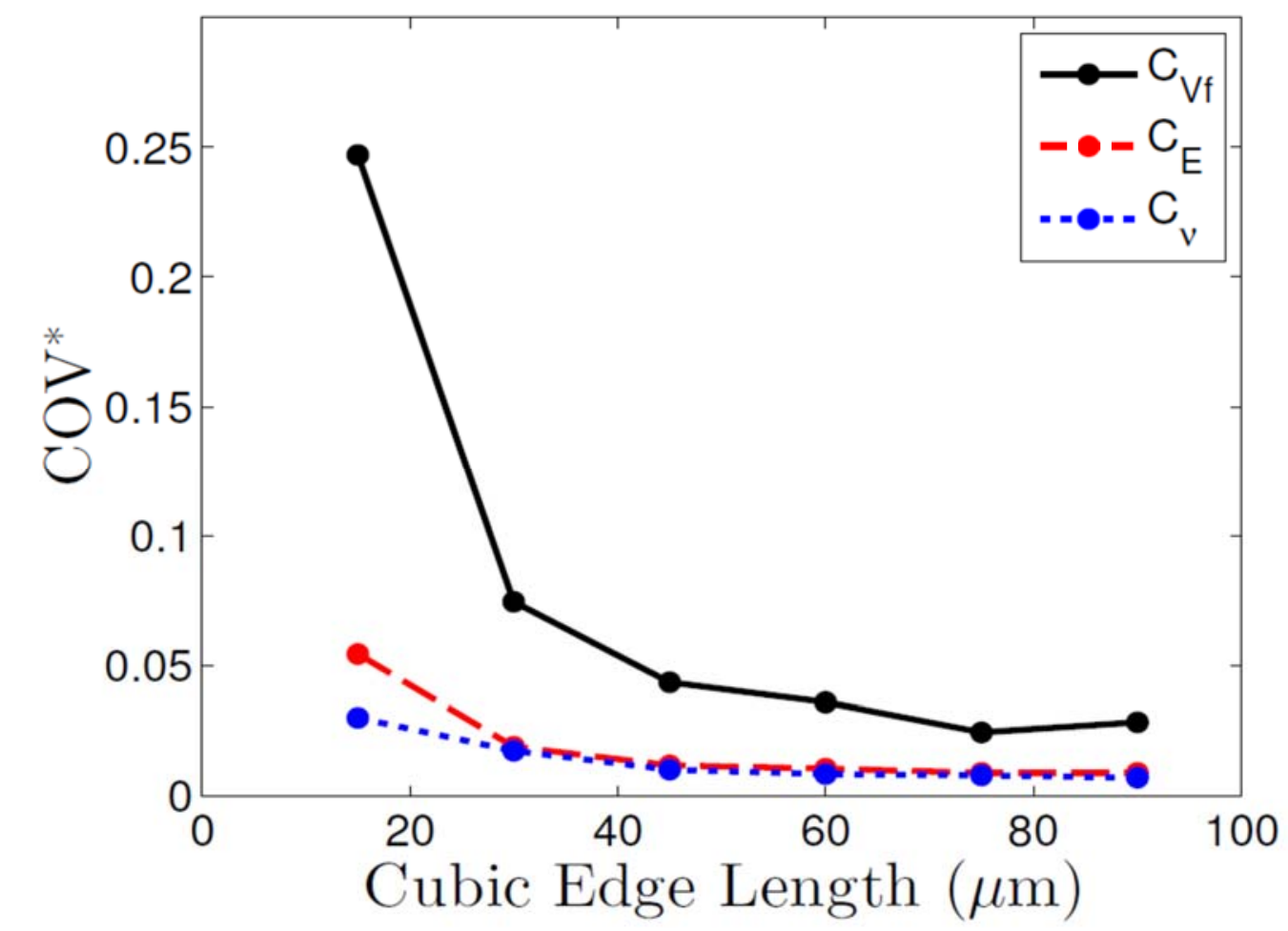

Fig. 7. Unbiased coefficient of variation $\left(\mathrm{COV}^{*}\right)$ of the copper volume fraction $\left(\mathrm{C}_{\mathrm{Vf}}-\right.$ black circles and solid line), Young's modulus $\left(\mathrm{C}_{\mathrm{E}}\right.$ - red circles and dashed line $)$ and Poisson's ratio $\left(\mathrm{C}_{v}-\right.$ blue circles and dotted line $)$. 
1

2

3

4

5

6

7

8

9

10

The Poisson's ratio, $\mathrm{C}_{v}$, is observed to be relatively insensitive to the volume element size, converging at approximately $45 \mu \mathrm{m}$. $\mathrm{C}_{v}$ decreases from 0.031 at $15 \mu \mathrm{m}$ to 0.007 at $90 \mu \mathrm{m}$. Since the sensitivity of Poisson's ratio to change is linearly dependent on the composition of each of the constituent phases, it is unsurprising that the effective Poisson's ratio of the composite is relatively insensitive to volume element size.

\subsection{Effect of Volume Fraction on Mechanical Properties}

\subsubsection{Young's modulus as a function of volume fraction}

The Young's modulus is plotted against the volume fraction for each volume element simulation, in Fig. 8, over a range of volume element sizes. The bounds of the H\&S analytical model, the rule of mixtures (ROM), and an experimental measurement (from Table 4) are also shown in Fig. 8. At small volume element sizes (i.e., $15 \mu \mathrm{m}$ and $30 \mu \mathrm{m}$ ), the variability in E and $\mathrm{V}_{\mathrm{f}}$ was large. This variability was somewhat reduced at $45 \mu \mathrm{m}$ and significantly reduced for $60 \mu \mathrm{m}$ volume element size and above. The FEA simulations of $\mathrm{E}$, based on experimental Tribeam microstructure input, cluster approximately $2 \%$ above the bulk measures from the manufacturer which are very close to the H\&S upper bound. This is consistent with our previous remark concerning the $1.2 \%$ porosity in the $\mathrm{W}-\mathrm{Cu}$ composite which would slightly reduce $\mathrm{E}$ when included in an FE simulation. Computational models of $\mathrm{W}-\mathrm{Cu}$ unit cells that include porosity have been completed and will be discussed in a future publication [75]. 


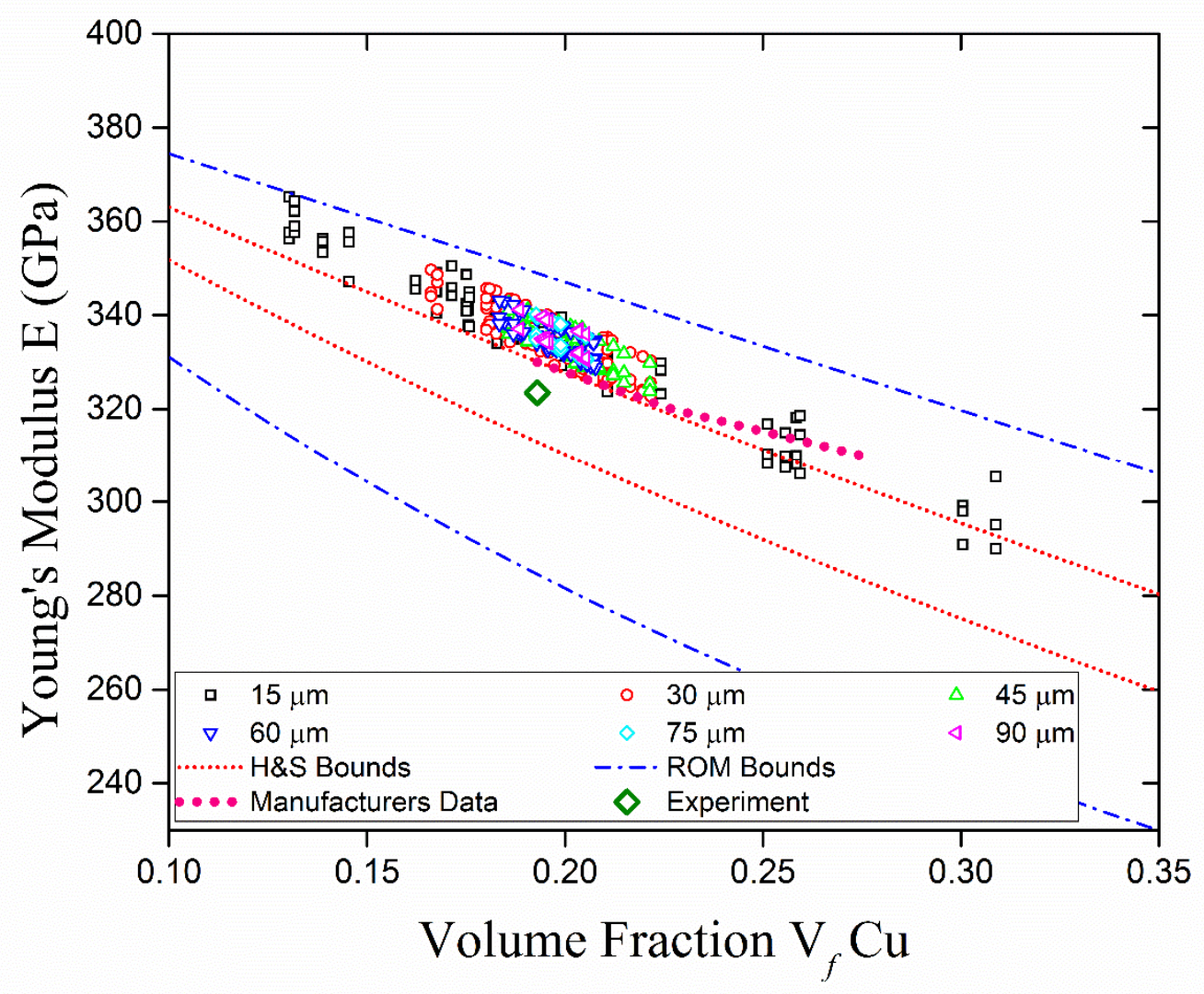

Fig. 8. Young's modulus (E) of each individual simulation plotted against volume fraction of each volume element. The results are compared with the Hashin and Shtrikman model bounds (H\&S), the Rule of Mixtures (ROM), an experimentally determined measurement and the manufacturer specifications [58].

\subsubsection{Poisson's ratio as a function of volume fraction}

The simulated Poisson's ratio for a range of volume element sizes is plotted against the volume fraction of each element in Fig. 9. In the case of the H\&S bounds for Poisson's ratio, as has been pointed out by Zimmerman [78], the calculation of these bounds for a twocomponent composite is not as straight forward as that for Young's modulus, on account of the different dependences of Poisson's ratio on the bulk and shear moduli. Poisson's ratio is an increasing function of bulk modulus, $K$, but a decreasing function of shear modulus, $G$, and as shown by Zimmerman [78], the correct H\&S bounds on Poisson's ratio, v, are

$$
\frac{\left(3 K_{1}-2 G_{2}\right)}{\left(6 K_{1}+2 G_{2}\right)} \leq v \leq \frac{\left(3 K_{2}-2 G_{1}\right)}{\left(6 K_{2}+2 G_{1}\right)}
$$

where the subscripts " 1 " and " 2 " indicate the lower and upper bounds in the H\&S values for $K$ and $G$, respectively [69]. These bounds on the H\&S model for $v$ are also shown in Fig. 9. 
The Poisson's ratio values simulated at volume element sizes of $15 \mu \mathrm{m}$ and $30 \mu \mathrm{m}$ had large variability, whereas Poisson's ratio calculated for volume element sizes of $45 \mu \mathrm{m}$ and above showed considerably less variability. At volume elements of 75 and $90 \mu \mathrm{m}$, the data are clustered above the lower bound suggested by the Zimmerman interpretation of the H\&S model [78] but certainly outside the lower bound predicted by the original H\&S expression [69].

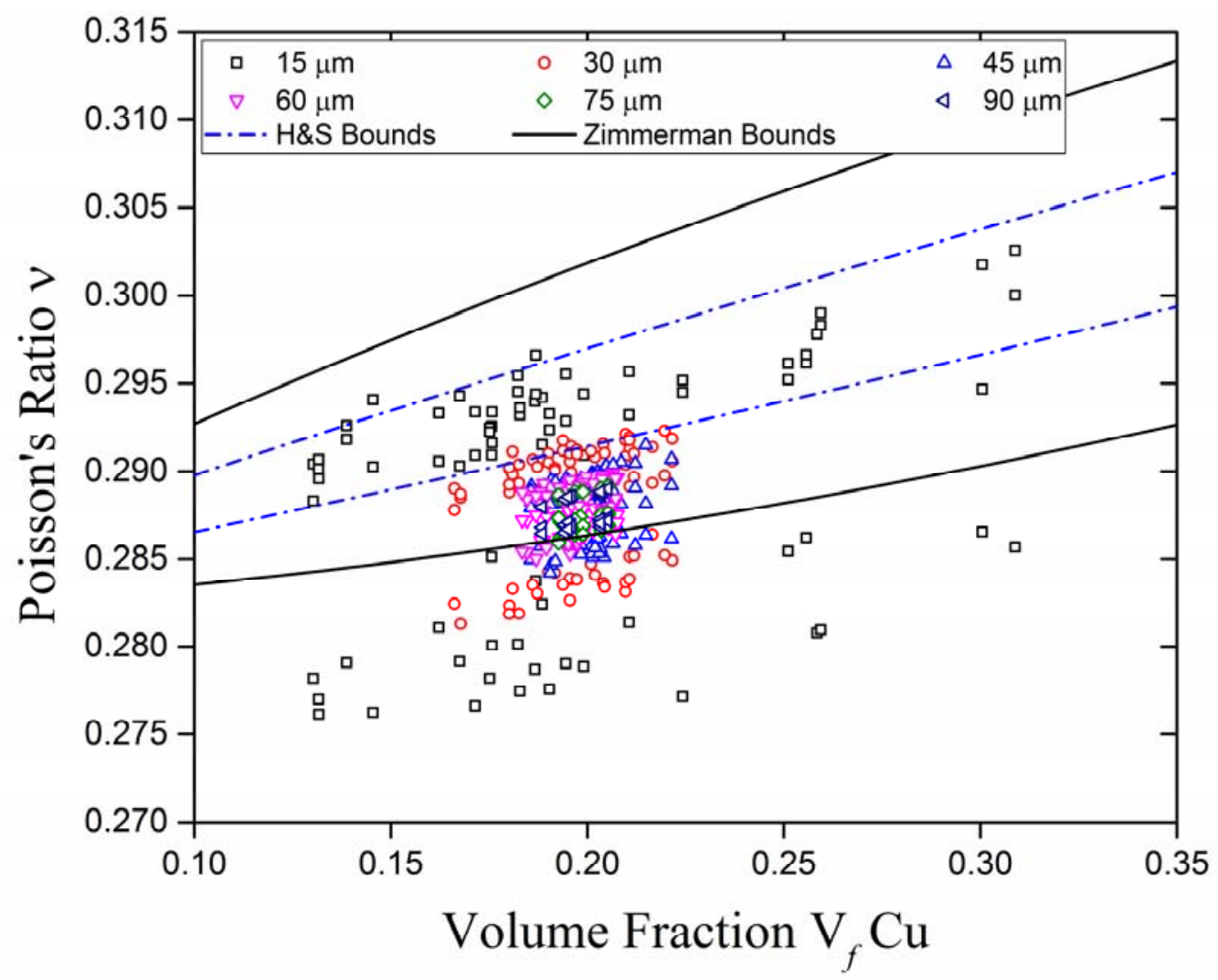

Fig. 9. Poisson's ratio $(v)$ of each individual simulation plotted against volume fraction of the volume element. The results are compared against the Hashin and Shtrikman model [H\&S] [69] as well as the interpretation of the H\&S model by Zimmerman [78].

\section{Conclusion}

The physical and elastic properties of a bi-continuous $\mathrm{W}-\mathrm{Cu}$ composite were modelled using the experimentally collected 3-D microstructural information captured with the Tribeam serial-sectioning technique. The investigated dataset showed isotropic 3D properties. The average value of the elastic properties, predicted at a volume equal to or larger than the 
1 minimum RVE were within approximately $3.6 \%$ of the experimentally determined value. The

2 variations between predictions in the principal directions were less than $2.1 \%$. The minimum

3 RVE depends upon the property being modelled. The volume fraction requires the largest size ( $90 \mu \mathrm{m}$ cube on a side) followed by Young's modulus ( $60 \mu \mathrm{m}$ cube) while Poisson's ratio requires the smallest RVE to reach stable values ( $45 \mu \mathrm{m}$ cube).

\section{Acknowledgements}

We should like to thank the Defence Materials Technology Centre (Project 4.2) for their technical and financial support for this research. We should also like to thank Mr. Michael Wang for his help in developing the image processing workflow developed during this research. A special thank you is also given to Mr. Jamie Whiteford from BAE Systems Australia for providing the $\mathrm{W}-\mathrm{Cu}$ materials used in this research. Funding from the UK Science and Technology Facilities Council for use of the ENGIN-X diffractometer located at the ISIS spallation neutron source at the Rutherford Appleton Laboratory is greatly appreciated.

\section{References}

[1] S.J. Zinkle, J.T. Busby, Structural materials for fission \& fusion energy, Materials Today 12 (11) (2009) 12-19.

[2] T.H. Squire, J. Marschall, Material property requirements for analysis and design of UHTC components in hypersonic applications, J. Euro. Ceram. Soc. 30 (11) (2010) 2239-2251.

[3] M.M. Gasik, Micromechanical modelling of functionally graded materials, Comp. Mater. Sci. 13 (1-3) (1998) 42-45.

[4] A. Rios, A. Martin-Meizoso, Thermomechanical modelling of copper matrix composites reinforced with tungsten fibres, 1st Int. Conf. on New Materials for Extreme Environment 59 (2008) 164- 168. 
1 [5] Y. Wang, S. Liang, J. Ren, Analysis of meso-scale damage and crack for CuW alloys

[6] N. Chawla, K. Chawla, Microstructure-based modeling of the deformation behavior of particle reinforced metal matrix composites, J. Mater. Sci. 41 (3) (2006) 913-925.

[7] A. Needleman, Void growth in an elastic-plastic medium, J. Appl. Mech. 39 (4) (1972) 964-970.

[8] V. Tvergaard, Influence of voids on shear band instabilities under plane strain conditions, Int. J. Fract. 17 (4) (1981) 389-407.

[9] V. Tvergaard, On localization in ductile materials containing spherical voids, Int. J. Fract. 18 (4) (1982) 237-252.

[10] J. Llorca, C. Gonzalez, Microstructural factors controlling the strength and ductility of particle-reinforced metal-matrix composites, J. Mech. Phys. Solids 46 (1) (1998) 1-28.

[11] J. Llorca, S. Suresh, A. Needleman, An experimental and numerical study of cyclic deformation in metal-matrix composites, Metall. Trans. A 23 (3) (1992) 919-934.

[12] N. Chawla, U. Habel, Y.-L. Shen, C. Andres, J. Jones, J. Allison, The effect of matrix microstructure on the tensile and fatigue behavior of $\mathrm{SiC}$ particle-reinforced $2080 \mathrm{Al}$ matrix composites, Metall. \& Mater. Trans. A 31 (2) (2000) 531-540.

[13] Y.-L. Shen, M. Finot, A. Needleman, S. Suresh, Effective elastic response of two-phase composites, Acta Metall. Mater. 42 (1) (1994) 77-97.

[14] Y.-L. Shen, Thermal expansion of metal-ceramic composites: a three-dimensional analysis, Mater. Sci. \& Eng. A 252 (2) (1998) 269-275.

[15] H. Chen, L. Meng, S. Chen, Y. Jiao, Y. Liu, Numerical investigation of microstructure effect on mechanical properties of bi-continuous and particulate reinforced composite materials, Comp. Mater. Sci. 122 (2016) 288-294. 
1 [16] O. Pierard, J. Llorca, J. Segurado, I. Doghri, Micromechanics of particle-reinforced elasto-viscoplastic composites: Finite element simulations versus affine homogenization, Int. J. Plasticity 23 (6) (2007) 1041-1060.

[17] J. Segurado, C. Gonzlez, J. Llorca, A numerical investigation of the effect of particle clustering on the mechanical properties of composites, Acta Mater. 51 (8) (2003) 23552369.

[18] J. Segurado, J. Llorca, Computational micromechanics of composites: The effect of particle spatial distribution, Mech. Mater. 38 (8-10) (2006) 873-883.

[19] J. Segurado, J. Llorca, A numerical approximation to the elastic properties of spherereinforced composites, J. Mech. Phys. Solids 50 (10) (2002) 2107-2121.

[20] J. LLorca, J. Segurado, Three-dimensional multiparticle cell simulations of deformation and damage in sphere-reinforced composites, Mater. Sci. \& Eng. A 365 (12) (2004) 267-274.

[21] C. Veyhl, I.V. Belova, G.E. Murch, T. Fiedler, Finite element analysis of the mechanical properties of cellular aluminium based on micro-computed tomography, Mater. Sci. \& Eng. A 528 (1314) (2011) 4550-4555.

[22] I. Watson, P. Lee, R. Dashwood, P. Young, Simulation of the mechanical properties of an aluminum matrix composite using X-ray microtomography, Metall. Mater. Trans. A 37 (3) (2006) 551-558.

[23] S. Youssef, E. Maire, R. Gaertner, Finite element modelling of the actual structure of cellular materials determined by X-ray tomography, Acta Mater. 53 (3) (2005) 719-730.

[24] J. Banhart, Advanced tomographic methods in materials research and engineering, Oxford University Press, 2008.

[25] M. Yanuka, F.A.L. Dullien, D.E. Elrick, Serial sectioning and digitization of porous media for two- and three-dimensional analysis and reconstruction, J. Micros. 135 (2) (1984) 159-168. 
1 [26] N. Chawla, V. Ganesh, B. Wunsch, Three-dimensional (3D) microstructure visualization and finite element modeling of the mechanical behavior of $\mathrm{SiC}$ particle reinforced aluminum composites, Scripta Mater. 51 (2) (2004) 161-165.

[27] Q. Wang, H. Zhang, H. Cai, Q. Fan, X. Zhang, Statistical three-dimensional reconstruction of continuous ceramic composites, Fin. Elem. in Anal. \& Design 114 (2016) 85-91.

[28] M.P. Echlin, A. Mottura, M. Wang, P.J. Mignone, D.P. Riley, G.V. Franks, T.M. Pollock, Three-dimensional characterization of the permeability of $\mathrm{W}-\mathrm{Cu}$ composites using a new TriBeam technique, Acta Mater. 64 (2014) 307-315.

[29] M.P. Echlin, A. Mottura, C.J. Torbet, T.M. Pollock, A new TriBeam system for threedimensional multimodal materials analysis, Rev. Sci. Inst. 83 (2) (2012) 023701023706.

[30] T. Kanit, S. Forest, I. Galliet, V. Mounoury, D. Jeulin, Determination of the size of the representative volume element for random composites: statistical and numerical approach, International J. Solids Struct. 40 (13-14) (2003) 3647-3679.

[31] G. Catalanotti, A. Katunin, Modelling the electro-mechanical properties of PPy/epoxy conductive composites Comp. Mater. Sci. 113 (2016) 88-97.

[32] N.K.Sharma, R.K. Mishra, S. Sharma, 3D micromechanical analysis of thermomechanical behaviour of $\mathrm{Al}_{2} \mathrm{O}_{3} / \mathrm{Al}$ metal matrix composites, Comp. Mater. Sci. 115 (2016) 192-201.

[33] S. Meille, E.J. Garboczi, Linear elastic properties of 2D and 3D models of porous materials made from elongated objects, Modell. Sim. Mater. Sci. \& Eng. 9 (5) (2001) 371-390.

[34] A. Roberts, E. Garboczi, Elastic properties of a tungsten-silver composite by reconstruction and computation, J. Mech. Phys. Solids 47 (10) (1999) 2029-2055.

[35] A. Roberts, E. Garboczi, Elastic moduli of model random three-dimensional closed-cell cellular solids, Acta Mater. 49 (2) (2001) 189-197. 
1 [36] W.N. Sharpe, B. Yuan, R.L. Edwards, A new technique for measuring the mechanical properties of thin films, J. Microelectromech. Systems 6 (3) (1997) 193-199.

[37] Y. Isono, T. Namazu, N. Terayama, Development of AFM tensile test technique for evaluating mechanical properties of sub-micron thick DLC films, J. Microelectromech. Systems 15 (1) (2006) 169-180.

[38] J.J. Vlassak, W.D. Nix, A new bulge test technique for the determination of Young's modulus and Poisson's ratio of thin films, J. Mater. Res. 7 (12) (1992) 3242-3249.

[39] Y. Xiang, X. Chen, J.J. Vlassak, Plane-strain bulge test for thin films, J. Mater. Res. 20 (9) (2005) 2360-2370.

[40] H.-Y. Lee, S.-J. Suh, S.-R. Kim, S.-Y. Park, Y.-C. Joo, Measurement of Poisson's ratio of a thin film on a substrate by combining x-ray diffraction with in situ substrate bending, Elec. Mater. Lett. 5 (1) (2009) 51-54.

[41] K.F. Badawi, P. Villain, P. Goudeau, P.-O. Renault, Measuring thin film and multilayer elastic constants by coupling in situ tensile testing with x-ray diffraction, Appl. Phys. Lett. 80 (25) (2002) 4705-4707.

[42] H.-C. Tsai, W. Fang, Determining the Poisson's ratio of thin film materials using resonant method, Sens. \& Actuat. A: Physical 103 (3) (2003) 377-383.

[43] T. Namazu, T. Fujii, M. Takahashi, M. Tanaka, S. Inoue, A simple experimental technique for measuring the Poisson's ratio of microstructures, J. Microelectromech. Syst. 22 (3) (2013) 625-636.

[44] P.K. Sahoo, S.S.K. Kamal, M. Premkumar, B. Sreedhar, S.K. Srivastava, L. Durai, Synthesis, characterization and densification of $\mathrm{WCu}$ nanocomposite powders, Int. J. Refract. Met. Hard Mater. 29 (4) (2011) 547-554.

[45] J. Cheng, C. Lei, E. Xiong, Y. Jiang, Y. Xia, Preparation and characterization of WCu nanopowders by a homogeneous precipitation process, J. Alloys Comp. 421 (12) (2006) 146-150. 
[46] S.N. Alam, Synthesis and characterization of W-Cu nanocomposites developed by mechanical alloying, Mater. Sci. \& Eng. A 433 (12) (2006) 161-168.

[47] T. Raghu, R. Sundaresan, P. Ramakrishnan, T.R. Mohan, Synthesis of nanocrystalline copper-tungsten alloys by mechanical alloying, Mater. Sci. \& Eng. A 304-306 (0) (2001) 438-441.

[48] A. Ibrahim, M. Abdallah, S.F. Mostafa, A.A. Hegazy, An experimental investigation on the WCu composites, Mater. \& Design 30 (4) (2009) 1398-1403.

[49] J. Das, A. Chakraborty, T.P. Bagchi, B. Sarma, Improvement of machinability of tungsten by copper infiltration technique, Int. J. Refract. Met. Hard Mater. 26 (6) (2008) $530-539$.

[50] W.S. Wang, K.S. Hwang, The effect of tungsten particle size on the processing and properties of infiltrated W-Cu compacts, Metall. Mater. Trans. A 29 (5) (1998) 15091516.

[51] H.-K. Kang, S.B. Kang, Effect of feedstock injection methods on oxidation behavior and microstructure of plasma sprayed W/Cu composites, Surf. \& Coat. Technol. 182 (1) (2004) 124-130.

[52] R.V. Minakova, I.N. Grechanyuk, V.V. Bukhanovsky, N.P. Rudnitsky, I. Mamuzic, Structure, electrical conductivity and mechanical characteristics of copper-tungsten composite obtained by electron beam physical vapour deposition (EB-PVD) technique, Trans. FAMENA 34 (2) (2010) 37-46.

[53] A. Abu-Oqail, M. Ghanim, M. El-Sheikh, A. El-Nikhaily, Effects of processing parameters of tungsten-copper composites, Int. J. Refract. Met. Hard Mater. 35 (0) (2012) 207-212.

[54] P. Ho, Q. Li, J. Fuh, Evaluation of WCu metal matrix composites produced by powder injection molding and liquid infiltration, Mater. Sci. \& Eng. A 485 (12) (2008) 657-663.

[55] E. Uhlmann, S. Piltz, K. Schauer, Micro milling of sintered tungsten-copper composite materials, J. Mater. Process. Technol. 167 (2-3) (2005) 402-407. 
1 [56] T. Bregel, W. Krauss-Vogt, R. Michal, K.E. Saeger, On the application of W/Cu materials in the fields of power engineering and plasma technology, IEEE Trans. Comp., Hybrids Manuf. Technol. 14 (1) (1991) 8-13.

[57] E. Divo, A. Kassab, R. Cavalleri, Application of the DRBEM to model ablation characteristics of a thrust vector control vane, Eng. Anal. Bound. Elem. 23 (8) (1999) 693-701.

[58] Plansee, Thermal Management, product catalogue 702 E.12.02 (2000). URL http://www.plansee.com/

[59] R.C. Gonzalez, R.E. Woods, S.L. Eddins, Digital Image Processing Using MATLAB, Second Edition, Gatesmark Publishing, 2009.

[60] R.C. Gonzalez, R.E. Woods, Digital Image Processing, Prentice Hall, 2002.

[61] G. Gerig, O. Kubler, R. Kikinis, F.A. Jolesz, Nonlinear anisotropic filtering of MRI data, IEEE Trans. Med. Imag. 11 (2) (1992) 221-232.

[62] Dassault Systemes, Dassault Systemes, France. URL http://www.3ds.com/products/simulia

[63] R. Lowrie, A.M. Gonas, Dynamic elastic properties of polycrystalline tungsten, $24^{\circ}$ $1800^{\circ} \mathrm{C}$, J. Appl. Phys. 36 (1965) 2189-2192.

[64] H.M. Ledbetter, Elastic constants of polycrystalline copper at low temperatures, Phys. Stat. Sol. (A) 66 (1981) 477-484.

[65] SIMULIA, Abaqus Analysis User's Manual, Version 6.11.

[66] M.F. Ashby, D.R.H. Jones, Engineering Materials 1: An Introduction to their Properties and Applications, Microstructures, Processing and Design, Ch. 6, Pergamon Press, 1991.

[67] B. Budiansky, On the elastic moduli of some heterogeneous materials, J. Mech. Phys. Solids 13 (4) (1965) 223-227. 
1 [68] J.D. Eshelby, The determination of the elastic field of an ellipsoidal inclusion, and related problems, Proc. Roy. Soc. Lond. Series A. Math. \& Phys. Sci. 241 (1226) (1957) 376-396.

[69] Z. Hashin, S. Shtrikman, A variational approach to the theory of the elastic behaviour of multiphase materials, J. Mech. Phys. Solids 11 (2) (1963) 127-140.

[70] T. Mura, Micromechanics of defects in solids, Comparative Studies in Overseas History, M. Nijho, 1987.

[71] J. Halpin, S. Tsai, Environmental factors estimation in composite materials design, AFML Trans. (1967) 67-423.

[72] N. Chawla, Y.-L. Shen, Mechanical behavior of particle reinforced metal matrix composites, Adv. Eng. Mater. 3 (6) (2001) 357-370.

[73] A.H. Cottrell, Mechanical Properties of Matter, Chapter 4, John Wiley \& Sons, 1964.

[74] F.R. Foulkes, Physical Chemistry for Engineering and Applied Sciences, Chapter 2, CRC Press, Taylor \& Francis Group, 2013.

[75] P.J. Mignone, Microstructural and Mechanical Modelling of Multiphase Materials: A Case Study on Copper-Infiltrated Tungsten (W-Cu) Composites, Ph.D. thesis, The University of Melbourne (2015).

[76] B. Ogunnaike, Random Phenomena: Fundamentals of Probability and Statistics for Engineers, Chapter 4, Taylor \& Francis, 2011.

[77] R. Sokal, F. Rohlf, Biometry, Chapter 4, W.H. Freeman, 1995.

[78] R.W. Zimmerman, Hashin-Shrikman bounds on the Poisson Ratio of a composite material, Mech. Res. Commun. 19 (6) (1992) 563-569. 